\title{
Bodegas, Baseball \& Ballads: The Democratization of Puerto Rican Identity
}

\author{
Ruth Masuka \\ University of Toronto \\ FAS Double Major in Diaspora \& Transnational Studies and Peace, Conflict \& Justice, \\ Minor in Music History \& Culture]
}

\section{A B S T R A C T}

Evident within many diasporic communities is a group consciousness and organization that operates in non-institutional spaces outside the realms of government agencies. The case of Puerto Ricans is no different and beyond collective organization, islanders in the diaspora went further in redefining the very criteria of Puerto Rican identity. This paper focuses on the migrant communities located in New York and the ways in which informal activities and non-institutional venues served as community centres. Food traditions, sporting competitions, and poetic practices all acted as cultural bases. Such activities fostered a democratic and participatory formation of Puerto Rican identity and played a critical role in the socioeconomic development of migrants. These spaces also provided room for the complex nuances of Puertoricanness that were overlooked or purposely excluded from dominant ideologies by both the American and Puerto Rican government. Looking at

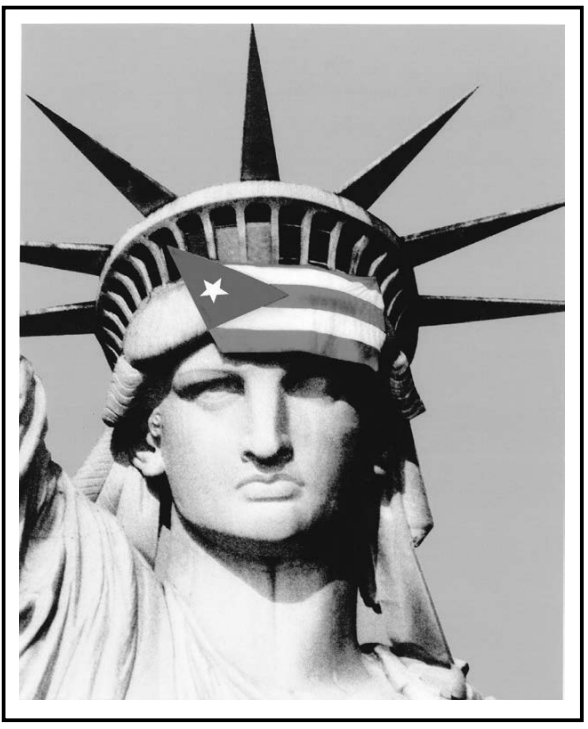

Keywords: New York City, Puerto Rico, Nuyorican, bodega, baseball, Boricuan, diaspora bodegas, athletic clubs, and the Nuyorican Poets Cafe, we can observe the vital role of spaces outside the state's control in facilitating an egalitarian and communal process of identity-making.

\section{B I O}

Ruth Masuka is a 3rd year student studying the intersections of peace and justice practices and art. Her research focuses on the use of non-institutional domains and informal spaces as catalysts for bottom-up group consciousness, capacity-building and community organizing. 
Long before institutions and governmental agencies intervened, Puerto Rican migrants arriving in New York took it upon themselves to organize their communities. In fact, their own frameworks of identity were often in stark contrast to official characterizations of them, reflecting their nuanced and complex interests and relationships to the homeland and their new home. This group consciousness took place through informal activities and non-institutional community spaces. Through these parts of life, Puerto Ricans not only reaffirmed the cultures of their home island, but developed unique traditions of the new island they found themselves. In this manner, it is critical to explore the arenas in which this development took place. These localities of cultural change served as critical bases for securing the rights for diasporic communities, transforming hegemonic ideologies of Puerto Rican identity, and exploring the tensions at the heart of the livelihoods of migrants. Looking specifically at the community institutions of bodegas, sport clubs, and the Nuyorican Poets Cafe, we can observe the importance of spaces that exist outside the control of the government which allow for a true democratic formation of identity.

Bodegas, far from being only commercial enterprises, have served as catalysts for economic and social development within the Puerto Rican communities since the first waves of migration to New York. Bodega owners, viewed with great respect due to their financial autonomy, continued to support their neighborhoods by stocking Puerto Rican goods, providing opportunities for newcomers, and simply being a familiar face. Shoppers would bond over similar grocery lists and shared hometowns. ' Yet with the forces of globalization and capitalism continually expanding, the enduring legacy of the bodega cannot be explained purely from an economic perspective; in fact, many economists anticipated the decline of the small grocery stores as Puerto Rican immigration fell and large food companies sold goods at cheaper prices. ${ }^{2}$ Their longevity can be explained by their multidimensionality, a fundamental condition of Puerto Rican character. Besides the physical needs of food purchases being met, the very intrinsic human emotion of belonging is fulfilled in every trip. ${ }^{3}$ The bodega's capacities of both convenience and community have made it not only a Puerto Rican institution, but a cherished New York cultural establishment that goes beyond ethnic or social status. Fulfilling these dual functions provided Puerto Ricans with a simple way to maintain identity but also transform it based on their new shared experiences of New York in those tight aisles.

Beyond the bodegas, another often overlooked mechanism of fostering group consciousness, especially within academic research, are sports leagues which were one of the original spaces of identity construction and community development

\footnotetext{
1 Sanabria, Carlos. The Bodega: a Cornerstone of Puerto Rican Barrios (the Justo Martí Collection). Centro Press, Center for Puerto Rican Studies, Hunter College, CUNY, 2016.

2 Hernandez, Sigfredo, and Carol Kaufman. "The Role of the Bodega in a U.S. Puerto Rican Community." Journal of Retailing, vol. 67, no. 4, 1991, pp. 375-396.

3 Otero, Solimar. "Barrio, Bodega, And Botanica Aesthetics.” Atlantic Studies, vol. 4, no. 2, 2007, pp. 173-194., doi:10.1080/14788810701510894.
} 
within the diaspora. The baseball games and boxing matches organized by athletic clubs became popular pastimes. The physical prowess of Puerto Ricans was on full display and beyond just trophies and medals, these sporting activities united what was otherwise a society at odds. Far from a static monolith, Puerto Rican consciousness and culture is multi-faceted and contradictory as shown by a 1998 referendum. Presented with the choices of statehood, independence, or commonwealth status, more than half of Puerto Rican voters chose none of the above. ${ }^{4}$

Regardless of these contradictions however, dating back to the 1950 s, Puerto Rican reports analyzed the embrace of baseball games on the Puerto Rican psyche and argued that 'destiny disunites us but sport unites us. ${ }^{5}$ At a very primal level, sporting restored a sense of pride to impoverished communities through winning which brought them together in a way no institutional agencies had achieved. Physicality was of great importance, especially within earlier generations of Puerto Rican migrants, and was perhaps the only time Puerto Ricans felt they had equal footing with their supposed superiors. To a community that faced social, economic and political constraints, sporting competitions provided the islanders with the self-determination America promised yet failed to give them. It offered hope for some and an opiate for others. Despite being granted American citizenship, sporting, especially baseball, still seems to be the strongest link between Puerto Rican identity and the United States. ${ }^{6}$ Sporting was the pinnacle of meritocracy; whoever was best would win. The confidence any victories caused transferred to how the islanders would navigate other areas of their lives and like bodegas, was not controlled by an external body that enforced government policies but remained out of touch with their experiences. These sporting leagues often expanded to become social clubs whereby several activities were planned outside of boxing rings and baseball diamonds to remain accessible to a growing Puerto Rican diaspora. As their function as community centres grew, so followed their function as a catalyst for group consciousness.

Bodegas and sporting leagues, while both serving the latent functions of community spaces, did not have an explicit purpose of active resistance against hegemonic definitions of Puerto Rican. While art forms of resistance within New York's Puerto Rican community are pervasive everyday performances, the Nuyorican Poets Cafe is an especially potent site for collaborative negotiation-based formations of identity. More than any other instrument of informal community building, the Nuyorican Poets Cafe embraced the fringes of Puertoricanness and examined the racial, linguistic, and transnational nuances of the barrio, both conceptualized as the fixed geographical neighborhood of East Harlem and a dynamic psychology the Puerto Ricans shared. Founded in 1973

\footnotetext{
${ }^{4}$ Gems, Gerald. "Puerto Rico: Sport and the Restoration of National Pride." The International Journal of Regional and Local Studies, vol. 1, no. 1, 2005, pp. 107-120., doi:10.1179/jrl.2005.1.1.107.

${ }^{5}$ Ibid

${ }^{6}$ Duany, Jorge. The Puerto Rican Nation on the Move: Identities on the Island in the United States. University of North Carolina Press, 2002.
} 
in the living room of poet Miguel Algarín, its modest roots demonstrated a rejection of imperial, class-based categorizations of individuals. Markets and money held no power over the artists who would occupy the space that eventually moved to a larger space to accommodate for expanding audiences.

The Nuyorican Poets Cafe challenged the easy equation of being born in Puerto Rico and speaking Spanish as the sole criteria for establishing one's Puertoricanness.8 The Nuyorican artistic tradition disfigured dominant notions of time, space, and language and based their idea of nationalism on artistic autonomy. The framing of identity was based on shared experiences rather than a specific outcome. ${ }^{9}$ With the likes of Pedro Pietri, the infamous critique of capitalism and in turn, America, and Jorge Brandon, the 'godfather' of Nuyorican literature, pushing this movement, the Nuyorican Poets Cafe soon became one of the most respected arts organizations in the city. As Algarín described it, the cafe was the home of the "democratization of the verse'. The themes of longing for return, economic exploitation, queer and racialized Puerto Ricans, and other inconvenient truths became the topics of an ongoing conversation between the performer and the audience.

Puerto Rican identity, constantly in motion, always finds itself at a crossroads. Often facets of this identity find themselves in contradiction with one another.

\footnotetext{
7 Dowdy, Michael. “They Must Be Re(Pre)Sented: Archiving Nuyorican Poetry’s 'Diasporous' Bodies.” Journal of Modern Literature, vol. 39, no. 3, 2016, p. 141., doi:10.2979/jmodelite.39.3.11.

8 Duany, Jorge. "The Rough Edges of Puerto Rican Identities: Race, Gender, and Transnationalism." Latin American Research Review, vol. 40, no. 3, 2005, pp. 177-190., doi:10.1353/lar.2005.0043.

${ }^{9}$ Noel, Urayoán. “On Out of Focus Nuyoricans, Noricuas, and Performance Identities.” Liminalities: A Journal of Performance Studies, vol. 10, no. 3-4, 2014, pp. 1-14., doi:1661910139.

10 Goergen, Juana Iris. "In Visible Movement: Nuyorican Poetry from the Sixties to Slam." Latino Studies, vol. 13, no. 4, 2015, pp. 573-574., doi:10.1057/1st.2015.37.

This is evidenced by persistent disputes regarding the direction of the post-colony. Rather than masking these disputes with simple categorizations of Puertoricanness, the communal activities and spaces of bodegas, athletic clubs and the Nuyorican Poets Cafe embraced and acknowledged the complexity of these characterizations. In some sense, these spaces offered a 'cultural citizenship', much more valuable than their American passport to its beholders as it was truly democratic. These institutions do not concern themselves so much with what defines Puerto Rican identity as they do with who gets to define it. In this framework, Puerto Ricans are all proud of their culture but for varying and distinct reasons. The freedom and agency Puerto Ricans had migrated to the United States had not been found within an American passport, but rather the truest forms of democracy were in the everyday activities where the power to define themselves was placed directly in the hands of the people. 